4 Differences in peptide oxidation between muscles in 12 months Spanish

5

6

7

8

9

10

11

12

13

14

15

16

17

18

19

20

21

22

23

24

25

26

27

28

29

\title{
dry-cured ham
}

Marta Gallego, Leticia Mora, and Fidel Toldrá*

8

(

Instituto de Agroquímica y Tecnología de Alimentos (CSIC), Avenue Agustín Escardino 7, 46980,

Paterna (Valencia), Spain

2

(1)

15

${ }^{*}$ Corresponding author: Tel: +34963900022 ext.2112; fax: +34963636301.

27

E-mail address: ftoldra@iata.csic.es 


\section{Abstract}

32 Oxidative modifications of proteins and peptides can negatively affect nutritional, 33 sensory and quality characteristics of dry-cured hams. The aim of this study was to use 34 a peptidomics strategy for the identification and relative quantification of oxidised 35 peptides in two different muscles, the external Semimembranosus (SM) and the internal 36 Biceps femoris (BF), from dry-cured hams of 12 months of curing. The analysis by 37 nanoliquid chromatography-tandem mass spectrometry identified peptides showing 38 oxidation at different amino acid residues such as methionine, cysteine, histidine, 39 tryptophan, and phenylalanine. The highest percentages of oxidised peptides identified 40 in $\mathrm{SM}$ and $\mathrm{BF}$ muscles were from pyruvate kinase protein (16.7 and $28.6 \%$, 41 respectively). The relative quantitation of oxidised peptides using mass spectrometry in 42 tandem label-free methodology evidenced significant differences between muscles, with 43 myosin and troponin fragments as main responsible peptides for the clustering of data. 44 The existing differences between BF and SM peptides were confirmed using MALDI 45 imaging mass spectrometry technique. The obtained results suggest that differences in 46 physicochemical characteristics such as water and salt contents between SM and BF 47 muscles could affect the quantity of peptide oxidation. This peptidomics approach has 48 allowed to analyse differences in peptide oxidation between dry-cured ham muscles as 49 well as to improve the knowledge about the oxidative processes that occur in dry-cured 50 hams.

52 Keywords: Oxidised peptides, mass spectrometry, label-free quantification, peptidomics, 53 MALDI imaging. 


\section{Introduction}

57 The transformation of pork meat into dry-cured ham is mainly due to the absorption and

58 diffusion of salt and the progressive dehydration of the meat, leading to different muscle

59 modifications regarding physicochemical characteristics such as $\mathrm{pH}, \mathrm{NaCl}$

60 concentration, moisture content and water activity. Moreover, several biochemical

61 reactions such as proteolysis and lipolysis take place during the dry-cured ham

62 processing, which involve changes in colour, flavour, taste, and texture giving rise to

63 the typical characteristics of the final product (Toldrá, 2004; Petrova, Aansen, Rustad,

64 \& Eikevik, 2015).

65 The characteristics of dry-cured hams can be affected by oxidative modifications of

66 proteins and peptides that commonly occur during their processing and storage (Estévez,

67 2011; Koutina, Jongberg, \& Skibsted, 2012; Soladoye, Juárez, Aalhus, Shand, \&

68 Estévez, 2015). Protein oxidation results in different chemical modifications including

69 the formation of carbonyl derivatives, cleavage of protein backbones, protein

70 crosslinking and modification of amino acid side chains. These oxidative modifications

71 can give rise to structural changes in proteins affecting their physical, chemical,

72 functional and nutritional properties (Lund, Heinonen, Baron, \& Estévez, 2011; Zhang,

73 Xiao, \& Ahn, 2013).

74 The analysis of protein oxidation can be performed by different methodologies

75 depending on the oxidative product to be measured. The formation of protein carbonyls

76 is one of the most notable modification resulting from protein oxidation, so that the

77 analytical procedures applied are usually based on the quantification of these

78 compounds by using the 2,4-dinitrophenylhydrazine (DNPH) derivatisation method,

79 fluorescence spectroscopy techniques or mass spectrometry (MS)-based methodologies

80 (Armenteros, Heinonen, Ollilainen, Toldrá, \& Estévez, 2009; Zhang et al., 2013). The 
81 combination of liquid chromatography (LC) with tandem MS is a valuable tool to 82 determine the specific oxidised amino acid and the nature of oxidative post-translational 83 modifications. This methodology allows the sensitive and accurate identification and 84 quantification of oxidised peptides as they have predictable mass shifts due to chemical 85 modifications of amino acid side chains and thus can be identified in the fragmentation 86 pattern (Schey \& Finley, 2000). Nevertheless, the analysis of oxidative modifications 87 continues to be challenging due to the complexity of the oxidative mechanisms that 88 generate a wide variety of oxidation products as well as the low abundance and 89 instability of some of them under the conditions of sample preparation and/or analysis 90 (Silva, Vitorino, Domingues, Spickett, \& Domingues, 2013; Verrastro, Pasha, Jensen, 91 Pitt, \& Spickett, 2015).

92 Few studies have been focused on studying the generation of oxidised peptides during 93 dry-cured ham processing to date (Gallego, Mora, Fraser, Aristoy, \& Toldrá, 2014; 94 Gallego, Mora, Aristoy, \& Toldrá, 2015a; Gallego, Mora, \& Toldrá, 2018), and to our 95 knowledge there are no studies evaluating the oxidation of peptides in different muscles. 96 The aim of this study was to assess potential differences in peptide oxidation between 97 Semimembranosus and Biceps femoris muscles of Spanish dry-cured ham of 12 months 98 of processing. To this end, a peptidomic approach has been used for the identification 99 and relative quantification of oxidised peptides in order to evaluate whether differences 100 between muscles affect peptide oxidation.

101

102 2. Materials and methods

$103 \quad$ 2.1 Dry-cured ham processing

104 Spanish dry-cured hams of 12 months of processing from 6-months-old pigs (Landrace $105 \mid \times$ Large White) were prepared according to the traditional procedure described by 
106 Escudero et al. (2013). It comprises a pre-salting period using a mixture of salt ( $\mathrm{NaCl})$,

107 nitrate and nitrite for $30 \mathrm{~min}$; a salting stage where hams were buried in salt and piled

108 up at $2-4{ }^{\circ} \mathrm{C}$ and $90-95 \%$ relative humidity (RH) for 12 days; a post-salting stage for 60

109 days at $4-5{ }^{\circ} \mathrm{C}$ and $75-85 \% \mathrm{RH}$; and finally a ripening-drying period at temperatures

110 increasing to $13-20{ }^{\circ} \mathrm{C}$ and $\mathrm{RH}$ decreasing to $70 \%$. Two different muscles, the external

111 Semimembranosus (SM) and the internal Biceps femoris (BF) muscles were selected for

112 the analysis $(n=3)$.

$113 \quad 2.2$ Determination of moisture and salt contents

114 The moisture content of each muscle was determined in $2 \mathrm{~g}$ of minced sample by drying

115 to constant weight at $175{ }^{\circ} \mathrm{C}$ using a halogen moisture analyser HB43 (Mettler Toledo,

116 Switzerland).

117 The determination of salt content in each muscle was done by ion chromatography 118 according to the methodology described by Armenteros, Aristoy, and Toldrá (2012).

119 For that, $5 \mathrm{~g}$ of minced sample was homogenised in water $(1: 10 ; \mathrm{w} / \mathrm{v})$ in a stomacher

120 (IUL Instruments, Barcelona, Spain) for $10 \mathrm{~min}$ at $4{ }^{\circ} \mathrm{C}$, and centrifuged $(12000 \underline{x g}, 20$

$\left.121 \mathrm{~min}, 4{ }^{\circ} \mathrm{C}\right)$. The supernatant was filtered through glass wool, diluted in water $(1: 100)$,

122 and immediately frozen at $-20{ }^{\circ} \mathrm{C}$ until use. Then, thawed samples were filtered through

123 a $0.45 \mu \mathrm{m}$ nylon membrane filter (Millipore, Bedford, MA, USA), and injected into the

124 ion chromatograph (Metrohm Advanced compact IC-861, Metrohm® Ltd., Herisau,

125 Switzerland) to determine the sodium $\left(\mathrm{Na}^{+}\right)$content. The column was a Metrosep C3

126 column $\left(250 \times 0.4 \mathrm{~mm}\right.$; Metrohm ${ }^{\circledR}$ Ltd. $)$, and $3 \mathrm{mM}$ HNO3 with 5\% acetone was used as

127 mobile phase at a flow rate of $1.2 \mathrm{~mL} / \mathrm{min}$. Collection and processing of data were done

128 using IC Net 2.3 software (Metrohm ${ }^{\circledR}$ Ltd.), and the concentration of the cation in each

129 sample was determined by plotting the peak areas against a calibration curve prepared

130 with standard solutions of $\mathrm{Na}^{+}(0.5-100 \mathrm{ppm})$ (Fluka, Switzerland, Sigma, St. Louis, 
131 MO, USA). Results of salt contents were expressed as percentage of sodium on dry weight basis of sample.

\section{$133 \quad 2.3$ Extraction of peptides}

134 Peptide extraction was carried out according to the method described by Escudero et al. 135 (2013), with some modifications. A total of $20 \mathrm{~g}$ sample of each sample (SM and BF 136 muscles) were minced and homogenised with $80 \mathrm{~mL}$ of $0.01 \mathrm{~N} \mathrm{HCl}$ for 8 min in a

137 stomacher (IUL Instrument, Barcelona, Spain) after removing the free $\mathrm{O}_{2}$ with $\mathrm{N}_{2}$ gas 138 injection. The homogenate was centrifuged (12000 xg, $\left.20 \mathrm{~min}, 4{ }^{\circ} \mathrm{C}\right)$ and filtered 139 through glass wool. Then, a total of $250 \mu 1$ of the supernatant was taken and

140 deproteinised by adding 3 volumes of ethanol $\left(2 \mathrm{~h},-20^{\circ} \mathrm{C}\right)$, centrifuged $(12000 \underline{x g}, 20$

$141 \mathrm{~min}, 4^{\circ} \mathrm{C}$ ), and finally dried in a rotatory evaporator and lyophilised.

\section{$142 \quad 2.4 \mathrm{nLC}-\mathrm{MS} / \mathrm{MS}$ analysis}

143 The identification of the peptides was performed by nanoliquid chromatography-tandem

144 mass spectrometry (nLC-MS/MS) using an Eksigent Nano-LC Ultra 1D Plus system

145 (Eksigent of AB Sciex, CA, USA) coupled to the quadrupole/time-of-flight (Q-ToF)

146 TripleTOF® 5600+ system (AB Sciex Instruments, MA, USA) with a nanoelectrospray

147 ionisation source (nESI).

148 Lyophilised samples were resuspended $(10 \mathrm{mg} / \mathrm{mL})$ in water with $0.1 \%$ of 149 trifluoroacetic acid (TFA). Then $15 \mu \mathrm{L}$ of each sample was cleaned and concentrated

150 using Zip-Tip $\mathrm{C}_{18}$ with standard bed format (Millipore Corporation, Bedford, MA)

151 according to manufacturer's guidelines. Peptide solutions were dried and resuspended in

$15220 \mu \mathrm{L}$ of $0.1 \%$ TFA, injecting a total of $5 \mu \mathrm{L}$ in the LC-MS/MS system. The sample

153 was preconcentrated on an Eksigent $\mathrm{C} 18$ trap column $(3 \mu \mathrm{m}, 350 \mu \mathrm{m} \times 0.5 \mathrm{~mm}$;

154 Eksigent of AB Sciex, CA, USA) using 0.1\% TFA as mobile phase at a flow rate of 3 $155 \mu \mathrm{L} / \mathrm{min}$ for $5 \mathrm{~min}$. The trap column was automatically switched in-line onto a nano- 
156 HPLC capillary column $(3 \mu \mathrm{m}, 75 \mu \mathrm{m} \times 12.3 \mathrm{~cm}, \mathrm{C} 18$; Nikkyo Technos Co., Ltd.,

157 Japan), using $0.1 \%$ formic acid in water was used-as solvent A, and $0.1 \%$ formic acid in

158 acetonitrile as solvent B. Chromatographic conditions were a linear gradient from $5 \%$ to

$15935 \%$ of solvent B over $90 \mathrm{~min}$, and $10 \mathrm{~min}$ from $35 \%$ to $65 \%$ of solvent $\mathrm{B}$, at a flow rate

160 of $0.3 \mu \mathrm{L} / \mathrm{min}$ and $30{ }^{\circ} \mathrm{C}$. The column outlet was coupled to $\mathrm{nESI}$. The $\mathrm{Q} / \mathrm{ToF}$ operated

161 in positive polarity and information-dependent acquisition mode, with $0.25 \mathrm{~s}$ MS scan

162 from 100 to $1250 \mathrm{~m} / \mathrm{z}$ and $0.05 \mathrm{~s}$ product ion scans from 100 to $1500 \mathrm{~m} / \mathrm{z}$ on the 50 most

163 intense 1 - 5 charged ions.

164 Data were processed using ProteinPilotTM v4.5 software (AB Sciex, MA, USA) for the

165 identification and quantification of peptides. The Paragon algorithm of ProteinPilot was

166 used to search in NCBI database with non-enzyme specificity, Sus scrofa taxonomy,

167 and including all possible post-traductional modifications.

168 The relative quantification of peptides was performed by using the label-free 169 methodology described by Gallego, Mora, Aristoy, and Toldrá (2015b). This approach

170 is based on the measurement of the integrated areas of extracted ion chromatograms

171 (XICs) from three replicates to determine the ratios for individual peptides. Peptides 172 were quantified using PeakView v1.1 software (AB Sciex, Framingham, MA, USA).

\section{$173 \quad 2.5$ MALDI-IMS}

174 Matrix-assisted laser desorption/ionization (MALDI) imaging mass spectrometry (IMS)

175 was used to study the spatial distribution of peptides in the two muscles (SM and BF) of 176 dry-cured ham tissue. After defining the two muscle areas in the tissue, frozen samples 177 stored at $-80^{\circ} \mathrm{C}$ were cut on a microtome at a $10 \mu \mathrm{m}$ thickness onto indium-tin-oxide 178 coated glass slides (Sigma, St. Louis, MO, USA). Sections were subjected to washing 179 steps using $70 \%$ ethanol and twice $100 \%$ ethanol to remove lipids, and then dried in a 180 desiccator for 30 minutes. Matrix CHCA, which contains $7 \mathrm{mg} / \mathrm{mL}$ of saturated $\alpha$ - 
181 cyano-4-hydroxycinnamic acid (Bruker Daltonics, Germany) in acetonitrile:water 182 (60:40) with $0.2 \%$ TFA, was applied using the HTX TM-Sprayer (HTX Technologies,

183 Chapel Hill, NC, USA). The plate was introduced in a 5800 MALDI-TOF/TOF (AB

184 Sciex, MA, USA) that was used in automatic positive-ion reflector mode for mass 185 analysis between 650 and 1800 Da. Previously, the plate and the acquisition method 186 were calibrated with a calibration mixture containing $\left[\mathrm{Glu}^{1}\right]$-Fibrinopeptide $\mathrm{B}$ and 187 Angiotensin II (Sigma, St. Louis, MO, USA) at a concentration of $1 \mathrm{nmol} / \mu \mathrm{L}$. Image 188 analysis was performed using TissueView v1.1 software (AB Sciex, MA, USA), and the 189 analysis of data was done using mMass software (http://www.mmass.org).

$190 \quad 2.6$ Statistical analysis

191 Statistical analysis including one-way analysis of variance (ANOVA) and Fisher's 192 multiple range tests were performed using XLSTAT 2011 v5.01 software (Addinsoft, 193 Barcelona, Spain) in order to determine significant differences in the contents of

194 moisture and salt between muscles. Results were the mean of 3 replicates \pm standard

195 error of mean, and differences were considered significantly at $p-\underline{P}<0.05$.

196 Data obtained from the relative quantification of oxidised peptides were statistically 197 analysed using MarkerView v1.3 software (AB Sciex, Framingham, MA, USA), 198 performing Principal Component Analysis (PCA) and Student's t-test $(p-\underline{P}<0.1)$ for 199 testing differences between dry-cured ham muscles.

201 3. Results and discussion

202 3.1. Moisture and salt contents

203 The moisture and salt contents were determined in SM and BF muscles of dry-cured

204 hams at the end of the processing (12 months) and shown in Table 1 . Values obtained 205 for the external SM muscle were $50.20 \pm 5.06 \%$ of water and $8.62 \pm 1.89 \%$ of salt 
\begin{tabular}{l|l}
206 & content, whereas for the internal BF muscle were $60.16 \pm 0.91 \%$ of water and $12.28 \pm$ \\
207 & $\underline{1.23 \% \text { of salt. Statistical analysis of these results indicated significant differences }(P<}$ \\
208 & $\underline{0.05) \text { between muscles for both parameters. BF muscle presents higher moisture and }}$
\end{tabular}

209 salt contents than SM muscle, because the dynamics of water loss and salt diffusion take

210 place from the surface (SM muscle) to the inner location (BF muscle). Processing

211 conditions and properties of hams such as weight, adiposity and muscle $\mathrm{pH}$ determine

212 the rate of dehydration, salt penetration and consequently the activity of proteolytic

213 enzymes, which play a major role in textural and sensory properties of dry-cured hams

214 (Toldrá, Rico, \& Flores, 1992; Ruiz-Ramírez, Arnau, Serra, \& Gou, 2005, 2006;

215 Giovanelli, Buratti, Laureati, \& Pagliarini, 2016). During $\underline{\text { In the first-initial step-stages }}$

216 of the eured hamdry-cured ham processing, SM muscle presents a high salt content that

217 can induce changes in solubility of sarcoplasmic proteins due to their denaturation

218 (Théron et al., 2011; Bermúdez, Franco, Carballo, Sentandreu, \& Lorenzo, 2014). On

219 the other hand, the delayed salt penetration and water migration in the internal BF

220 muscle would lead to a high degradation of sarcoplasmic and myofibrillar proteins as

221 the action of proteases is not affected by these processing conditions (Théron et al.,

222 2011; Bermúdez et al., 2014).

223 3.2. Identification of peptides

224 Peptide extracts from SM and BF muscles were analysed by nLC-MS/MS for the 225 identification of peptides. More than 5,000 peptides from different proteins were 226 identified in the peptide extracts of both muscles, and the study was focused on those 227 showing oxidative modifications. Table $z$ - 1 shows main proteins from which the 228 identified peptides were derived, including myofibrillar proteins such as actin, myosin, 229 titin, and troponin, and sarcoplasmic proteins such as glycolytic enzymes. The numbers 230 of oxidised and unoxidised peptides identified for each protein as well as the total 
231 percentage of oxidised peptides are given in Table $\underline{2} \underline{1}$. In SM muscle, oxidised peptides

232 were mainly derived from myosin, creatine kinase and beta-enolase proteins. However,

233 pyruvate kinase and phosphoglycerate kinase showed the highest percentages of

234 oxidised peptides (16.67\% and $7.14 \%$, respectively). In BF muscle, peptides showing

235 oxidation were mainly derived from actin, myosin and beta-enolase, whereas the highest

236 percentage of oxidised peptides was also observed for pyruvate kinase $(28.57 \%)$.

237 It has been reported that the salt used in the dry-cured ham processing could exert a pro238 oxidative effect because sodium chloride can initiate protein oxidation by lipid

239 oxidative products, change the structure and solubility of proteins increasing their 240 susceptibility to be oxidised, and activate heme pigments that would promote 241 carbonylation and cross-linking of proteins (Souza et al., 2013: Soladoye et al., 2015).

242 In this regard, the study carried out by Wang et al. (2011) evidenced the intense 243 degradation of proteins in SM and BF muscles and the increase of protein oxidation 244 during the salting stage of dry-cured Xuanwei ham, showing higher values of carbonyl 245 contents at the end of salting in SM than BF due to the external muscle is exposed to 246 oxygen more easily. Also Koutina et al. (2012) reported an extended formation of 247 protein radicals and protein carbonyls during the first stages of Parma dry-cured ham 248 processing, faster for SM than BF due to the better availability of oxygen and higher 249 salt content in the external SM muscle. However, these oxidative processes tended to be 250 stabilised toward the final stages of maturation and similar values were found in both $251 \mathrm{SM}$ and BF muscles at the end of the processing (Koutina et al., 2012). The results of 252 the present study also showed minor differences between muscles in terms of the 253 number of peptides with oxidative modifications and main proteins from which they 254 were derived despite the significant differences in salt content between muscles. In fact, 255 the identified oxidised peptides could derive from the degradation of other peptides 
256 showing this modification in earlier processing steps such as post-salting stage (Gallego 257 et al., 2014).

258 Some of the identified peptides in this study showed several oxidative modifications in

259 their sequences. So, Table $3-2$ indicates the number of oxidised peptides identified 260 according to the addition of one, two, or three oxygen atoms at different amino acid 261 residues such as methionine (Met), cysteine (Cys), histidine (His), tryptophan (Trp), and 262 phenylalanine (Phe). Met was the residue that underwent more oxidative modifications, 263 representing around $77 \%$ of the oxidised peptides identified in SM muscle and $84 \%$ of 264 those identified in BF muscle. Cys residues were mainly modified by the addition of 265 two oxygen atoms in the SM muscle, and even trioxidations on this residue were 266 observed in both muscles. His and Trp were oxidised to a lesser degree, and oxidation 267 of Phe was only detected in peptides from BF muscle.

268 Several studies have identified amino acid oxidations in peptides derived from different myofibrillar proteins in dry-cured hams, mainly involving Met (Gallego et al., 2014;

270 Gallego et al., 2015a), but also proline (Pro) and Trp residues (Gallego et al., 2018). 271 Some amino acid residues have an intrinsic susceptibility to be oxidised due to its 272 structure, but their neighboring residues and position within the peptide sequence also 273 determine their oxidation (Estévez, 2011; Ghesquière \& Gevaert, 2014). The amino 274 acids Met and Cys are very susceptible to oxidative modifications due to the reactive 275 sulfur atoms contained in their structures. The oxidation of Met generates sulfoxide as 276 main oxidative product, which can be further oxidised to sulfone (Stadtman, Moskovitz, 277 \& Levine, 2003). On the other hand, Cys can be oxidised to sulfenic acid, sulfinic acid 278 and sulfonic acid by addition of one, two or three oxygen atoms, respectively (Silva et 279 al., 2013; Zhang et al., 2013). Some of the oxidative modifications of Met and Cys 280 residues are reversible and have been described to be involved in antioxidant 
281 mechanisms and changes on conformation, solubility, funtionality, and proteolytic 282 susceptibility of peptides (Stadtman et al., 2003). Aromatic amino acids such as His, 283 Trp, and Phe need more severe conditions to be oxidised, and mainly undergo 284 hydroxylation reactions (Stadtman \& Levine, 2003).

\section{3.3. Quantification of oxidised peptides and MALDI -IMS}

286 In order to evaluate whether the observed differences in salt content between external

287 and internal muscles could affect peptide oxidation at quantitative level, a relative 288 quantification of the oxidised peptides identified in SM and BF muscles was done using 289 a label-free methodology based on peak intensity measurements. A Principal 290 Component Analysis (PCA) score plot was performed to stablish statistical differences 291 between muscles according to the influence of the oxidised peptides and variance 292 among them (Figure 1A). Principal component 1 (PC 1) explained the $37.9 \%$ of the 293 variability in the dataset while PC 2 was responsible for the $23.4 \%$ of variance within 294 the dataset, allowing the differentiation between SM and BF muscles. Additionally, the 295 loading plot (Figure 1B) revealed the oxidised peptides with the highest influence for 296 the description of the discriminant components. Statistical analysis using Student's t297 test showed that peptides AP[Oxi]KKPEPKKDDAKA, 298 APKKP[Oxi]EPKKDDAKAAAKAAPAPAPAPAPAPEPPKEPE, and 299 APKKP[Oxi]EPKKDDAKAAAKAAPAPAPAPAPAPEPPKEPEFD derived from the 300 degradation of myosin light chain protein, as well as 301 GDEEKRHRAITARRQHLKSVM[Oxi]LQIAATELEKE derived from troponin I 302 protein were the main peptides responsible for differences observed between SM and 303 BF muscles $(p-\underline{P}<0.1)$. In this regard, peptides derived from myosin protein had 304 already been described as the most influential at the end of the processing of 9 months 305 Spanish dry-cured ham (Gallego, Mora, \& Toldrá, 2016; Gallego et al., 2018). 
306 Up to date, little is known about the effect of dry-cured ham processing conditions on

307 peptide oxidation. The present work suggests that differences in physicochemical

308 characteristics such as water and salt contents between SM and BF muscles could affect

309 peptide oxidation at quantitative level. Recently, Gallego et al. (2018) studied the

310 evolution of oxidised peptides throughout the processing of 9 months dry-cured ham,

311 evidencing quantitative differences in peptide oxidation at different processing times.

312 That work suggested that curing salts and specific processing conditions could lead to

313 an increase of oxidative reactions as the processing of dry-cured ham progressed, but

314 further studies are still needed.

315 MS techniques such as LC-MS/MS allow a fast, sensitive, precise and specific analysis

316 of peptides and post-translational modifications, and peptidomics has proven to be a

317 useful tool to obtain valuable information at peptide level. However, novel strategies

318 such as MS imaging are a very useful tools for the spatio-chemical characterisation of

319 biomolecules from food samples, the localisation of biomarkers, or the increase of

320 knowledge about food metabolomics (Li et al., 2016). MALDI-IMS is one of the main

321 techniques currently used in food science research to visualise the distribution of

322 nutrients, elements or contaminants in a single measurement. However, protein and

323 peptide imaging is challenging and difficult to standardise and so, few studies on food

324 products have been undertaken to that end yet (Yoshimura, Goto-Inoue, Moriyama, \&

325 Zaima, 2016).

326 In this work, a preliminary study using MALDI-IMS has been done in order

327 to obtain an overview of the spatial distribution of peptides in the SM and BF muscles

328 of dry-cured ham tissue. Figure $2 \mathrm{~A}$ reveals a spatial heterogeneity of the peptide ion

329 intensities between muscles, and Figure 2B shows the obtained MALDI-TOF MS

330 spectrum from 650 to $1800 \mathrm{~m} / \mathrm{z}$. These results indicate a higher amount of peptides in 
331 SM than BF muscle, despite a more intense proteolysis would be expected in the

332 internal muscle. This fact could be due to peptides present in the BF muscle are of a

333 smaller size than those analysed in the selected mass range, so further studies would be

334 needed for better evaluating peptide differences between dry-cured ham muscles. Up to

335 date, MALDI-IMS has only been applied in order to resolve the distribution of lipids in

336 beef meat (Zaima et al., 2011; Dyer et al., 2014), whereas other imaging techniques

337 such as magnetic resonance imaging (MRI) have been used for the characterisation of

338 dry-cured hams in terms of monitoring changes between muscles or during processing

339 (Fantazzini, Gombia, Schembri, Simoncini, \& Virgili, 2009; Bajd, Škrlep, Čandek-

340 Potokar, Vidmar, \& Serša, 2016). Despite MRI and IMS can provide complementary

341 data about localişzation and chemical characterisation of biomolecules, MALDI-IMS

342 seems a promising tool in food-based applications that require fast, cheap and accurate

343 analysis, and the high resolution provided by tandem mass spectrometers is not

344 necessary (Canela, Rodríguez, Baiges, Nadal, \& Arola, 2016). Thus, future studies

345 based on imaging of proteins and peptides in dry cured hams could be used to localise

346 differences between samples associated with tissue types, physicochemical

347 eharacteristics, processing conditions, genetic differences as well as to assess food

quality, safety and authenticity.

350 4. Conclusions

351 The use of peptidomics has allowed the study of differences in peptide oxidation

352 between the external SM muscle and the internal BF muscle from 12 months dry-cured

353 hams. Numerous peptides were identified showing oxidation at different amino acid

354 residues such as methionine, cysteine, histidine, tryptophan, and phenylalanine.

355 Pyruvate kinase was the protein showing the highest percentage of oxidised peptides in 
356 both muscles, whereas the label-free quantification showed that three peptides derived

357 from myosin light chain protein and one peptide derived from troponin I were the main

358 responsible for oxidative differences between SM and BF muscles. On the other hand,

359 MALDI imaging mass spectrometry was used for the simultaneous mapping of peptides

360 present in both sample sections, confirming the potential of this technique to determine

361 differences between samples. Future studies based on imaging of proteins and peptides

362 in dry-cured hams could be used to localise differences between samples associated

363 with tissue types, physicochemical characteristics, processing conditions, genetic

364 differences as well as to assess food quality, safety and authenticity.

365 The results obtained in this study suggest that differences in physicochemical

366 characteristics between muscles such as water and salt contents could affect oxidation at

367 peptide level, allowing a better understanding of the oxidative processes that take place

368 in the dry-cured ham currently focused on protein oxidation.

369

370 Acknowledgements

371 Grant AGL2014-57367-R from MINECO and FEDER funds are acknowledged. Ramón

372 y Cajal 2016 postdoctoral contract to LM is also acknowledged. The proteomic analysis

373 was performed in the proteomics facility of SCSIE University of Valencia that belongs

374 to ProteoRed, PRB2-ISCIII, (IPT13/0001 - ISCIII-SGEFI / FEDER). The authors thank

375 L. Valero and L. Cantero for MALDI imaging mass spectrometry analysis.

376

377 References

378 Armenteros, M., Heinonen, M., Ollilainen, V., Toldrá, F., \& Estévez, M. (2009).

379 Analysis of protein carbonyls in meat products by using the DNPH-method, 
380 fluorescence spectroscopy and liquid chromatography-electrospray ionisation-mass 381 spectrometry (LC-ESI-MS). Meat Science, 83, 104-112.

382 Armenteros, M., Aristoy, M. C., \& Toldrá, F. (2012). Evolution of nitrate and nitrite 383 during the processing of dry-cured ham with partial replacement of $\mathrm{NaCl}$ by other 384 chloride salts. Meat Science, 91, 378-381.

385 Bajd, F., Škrlep, M., Čandek-Potokar, M., Vidmar, J., \& Serša, I. (2016). Application of 386 quantitative magnetization transfer magnetic resonance imaging for characterization 387 of dry-cured hams. Meat Science, 122, 109-118.

388 Bermúdez, R., Franco, D., Carballo, J., Sentandreu, M. A., \& Lorenzo, J. M. (2014). 389 Influence of muscle type on the evolution of free amino acids and sarcoplasmic and 390 myofibrillar proteins through the manufacturing process of Celta dry-cured ham. $391 \quad$ Food Research International, 56, 226-235.

392 Canela, N., Rodríguez, M. Á., Baiges, I., Nadal, P., \& Arola, L. (2016). Foodomics 393 imaging by mass spectrometry and magnetic resonance. Electrophoresis, 37(13), $394 \quad 1748-1767$.

395 Dyer, J. M., Deb-Choudhury, S., Cornellison, C. D., Krsinic, G., Dobbie, P., Rosenvold, 396 K., \& Clerens, S. (2014). Spatial and temporal mass spectrometric profiling and 397 imaging of lipid degradation in bovine M. longissimus dorsi lumborum. Journal of 398 Food Composition and Analysis, 33(2), 203-209.

399 Escudero, E., Mora, L., Fraser, P. D., Aristoy, M. C., Arihara, K., \& Toldrá, F. (2013). $400 \quad$ Purification and identification of antihypertensive peptides in Spanish dry-cured ham. 401 Journal of Proteomics, 78, 499-507.

402 Estévez, M. (2011). Protein carbonyls in meat systems: a review. Meat Science. 89, $403 \quad 259-279$. 
404 Fantazzini, P., Gombia, M., Schembri, P., Simoncini, N., \& Virgili, R. (2009). Use of 405 magnetic resonance imaging for monitoring Parma dry-cured ham processing. Meat $406 \quad$ Science, $82(2), 219-227$.

407 Gallego, M., Mora, L., Fraser, P.D., Aristoy, M.A, \& Toldrá, F. (2014). Degradation of 408 LIM domain-binding protein three during processing of Spanish dry-cured ham. $409 \quad$ Food Chemistry, 149, 121-128.

410 Gallego, M., Mora, L., Aristoy, M. C., \& Toldrá, F. (2015a). Evidence of peptide 411 oxidation from major myofibrillar proteins in dry-cured ham. Food Chemistry, 187, $412 \quad 230-235$.

413 Gallego, M., Mora, L., Aristoy, M. C., \& Toldrá, F. (2015b) Optimisation of a simple 414 and reliable label-free methodology for the relative quantitation of raw pork meat 415 proteins. Food Chemistry, 182, 74-80.

416 Gallego, M., Mora, L., \& Toldrá, F. (2016). Peptidomics as a tool for quality control in 417 dry-cured ham processing. Journal of Proteomics, 147, 98-107.

418 Gallego, M., Mora, L., \& Toldrá, F. (2018). Evolution of oxidised peptides during the 419 processing of 9 months Spanish dry-cured ham. Food Chemistry, 239, 823-830.

420 Ghesquière, B., \& Gevaert, K. (2014). Proteomics methods to study methionine $421 \quad$ oxidation. Mass Spectrometry Reviews, 33 (2), 147-156.

422 Giovanelli, G., Buratti, S., Laureati, M., \& Pagliarini, E. (2016). Evolution of 423 physicochemical, morphological and aromatic characteristics of Italian PDO dry424 cured hams during processing. European Food Research and Technology, 242 (7), $425 \quad 1117-1127$.

426 Koutina, G., Jongberg, S. \& Skibsted, L.H,.(2012). Protein and lipid oxidation in Parma 427 ham during production. Journal of Agricultural and Food Chemistry, 60(38), 9737$428 \quad 9745$. 
429 Li, B., Dunham, S. J., Dong, Y., Yoon, S., Zeng, M., \& Sweedler, J. V. (2016).

430 Analytical capabilities of mass spectrometry imaging and its potential applications in 431 food science. Trends in Food Science \& Technology, 47, 50-63.

432 Lund, M.N., Heinonen, M., Baron, C.P., \& Estévez, M. (2011). Protein oxidation in 433 muscle foods: A review. Molecular Nutrition and Food Research, 55 (1), 83-95.

434 Petrova, I., Aansen, I. M., Rustad, T., \& Eikevik, T. M. (2015) Manufacture of dry435 cured ham: a review. Part I. Biochemical changes during the technological process. 436 European Food Research and Technology, 241 (5), 587-599.

437 Ruiz-Ramírez, J., Arnau, J., Serra, X., \& Gou, P. (2005). Relationship between water 438 content, $\mathrm{NaCl}$ content, $\mathrm{pH}$ and texture parameters in dry-cured muscles. Meat $439 \quad$ Science, $70(4), 579-587$.

440 Ruiz-Ramírez, J., Arnau, J., Serra, X., \& Gou, P. (2006). Effect of pH (24), NaCl 441 content and proteolysis index on the relationship between water content and texture 442 parameters in biceps femoris and semimembranosus muscles in dry-cured ham. Meat $443 \quad$ Science, $72(2), 185-194$.

444 Schey, K. L., \& Finley, E. L. (2000). Identification of peptide oxidation by tandem mass $445 \quad$ spectrometry. Accounts of Chemical Research, 33 (5), 299-306.

446 Silva, A. M., Vitorino, R., Domingues, M. R. M., Spickett, C. M., \& Domingues, P. 447 (2013). Post-translational modifications and mass spectrometry detection. Free $448 \quad$ Radical Biology and Medicine, 65, 925-941.

449 Soladoye, O. P., Juárez, M. L., Aalhus, J. L., Shand, P., \& Estévez, M. (2015). Protein 450 oxidation in processed meat: Mechanisms and potential implications on human 451 health. Comprehensive Reviews in Food Science and Food Safety, 14 (2), 106-122. 
452 Souza, M. A., Visentainer, J. V., Carvalho, R. H., Garcia, F., Ida, E. I., \& Shimokomaki,

453 M. (2013). Lipid and protein oxidation in charqui meat and jerked beef. Brazilian 454 Archives of Biology and Technology, 56 (1), 107-112.

455 Stadtman, E. R., \& Levine, R. L. (2003). Free radical-mediated oxidation of free amino 456 acids and amino acid residues in proteins. Amino acids, 25 (3-4), 207-218.

Stadtman, E. R., Moskovitz, J., \& Levine, R. L. (2003). Oxidation of methionine residues of proteins: biological consequences. Antioxidants and Redox Signaling, 5 (5), 577-582.

Théron, L., Sayd, T., Pinguet, J., Chambon, C., Robert, N., \& Santé-Lhoutellier, V. (2011). Proteomic analysis of semimembranosus and biceps femoris muscles from Bayonne dry-cured ham. Meat Science, 88 (1), 82-90.

Toldrá, F., Rico, E., \& Flores, M. (1992). Activities of pork muscle proteases in model cured meat systems. Biochimie, 74 (3), 291-296.

Toldrá, F. (2004). Dry-cured ham. In Y. H. Hui, L. Meunier-Goddik, A. S. Hansen, J. Josephsen, W. K. Nip, P. S. Stanfield, \& F. Toldrá (Eds.), Handbook of food and beverage fermentation technology (pp 369-384). New York: Marcel-Dekker.

Verrastro, I., Pasha, S., Jensen, K. T., Pitt, A. R., \& Spickett, C. M. (2015). Mass spectrometry-based methods for identifying oxidized proteins in disease: advances and challenges. Biomolecules, 5 (2), 378-411.

Wang, Z., Xu, Y., Zhang, J., Li, X., Lin, Z., \& Ma, C. (2011). Proteolysis, protein oxidation and protease activity in dry-cured Xuanwei ham during the salting stages. International Journal of Food Science and Technology, 46 (7), 1370-1377.

Yoshimura, Y., Goto-Inoue, N., Moriyama, T., \& Zaima, N. (2016). Significant advancement of mass spectrometry imaging for food chemistry. Food Chemistry, $210,200-211$. 
477 Zaima, N., Goto-Inoue, N., Hayasaka, T., Enomoto, H., \& Setou, M. (2011).

1 3

478 Authenticity assessment of beef origin by principal component analysis of matrix479 assisted laser desorption/ionization mass spectrometric data. Analytical and $480 \quad$ Bioanalytical Chemistry, 400 (7), 1865-1871.

481 Zhang, W., Xiao, S., \& Ahn, D. U. (2013). Protein oxidation: basic principles and 482 implications for meat quality. Critical Reviews in Food Science and Nutrition, 53 $483 \quad(11), 1191-1201$

484

485 


\section{FIGURE CAPTIONS}

1

487 Figure 1. A) Principal Component Analysis (PCA) score plot to assess the variance 488 among the oxidised peptides of Semimembranosus (SM) and Bicep femoris (BF) 489 muscles in three replicates $(n=3)$. B) Loading plot showing the oxidised peptides 490 affecting the score plot distribution. The main peptides responsible for statistical 491 differences between muscles are shown in red.

492 Figure 2. A) MALDI imaging mass spectrometry (IMS) of dry-cured ham tissue, 493 showing the spatial distribution of peptides in Semimembranosus (SM) and Bicep 494 femoris (BF) muscles. B) MALDI-TOF MS spectrum from 650 to $1800 \mathrm{~m} / \mathrm{z}$. 495 
A)

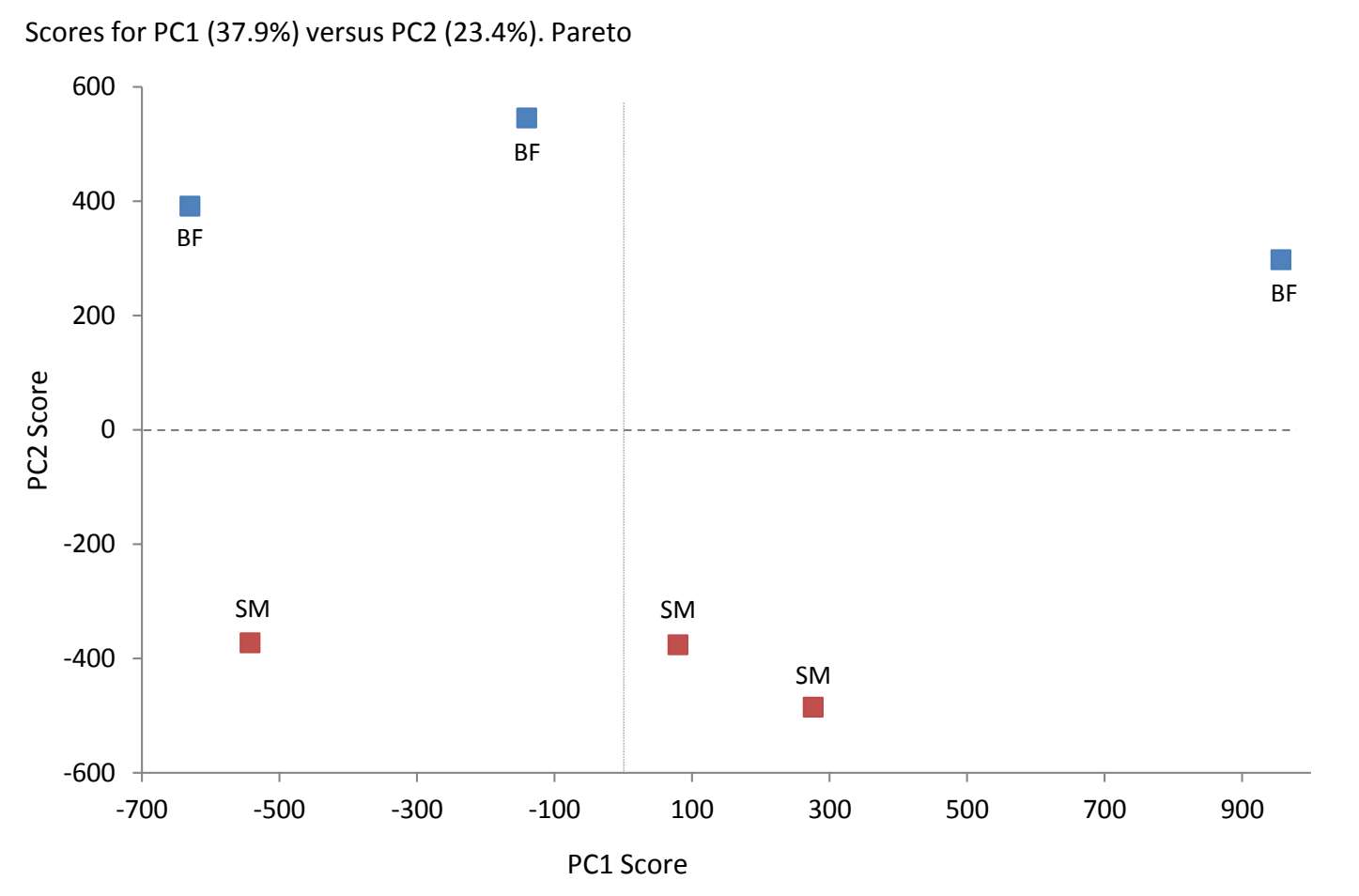

B)

Loadings for PC1 (37.9\%) versus PC2 (23.4\%). Pareto

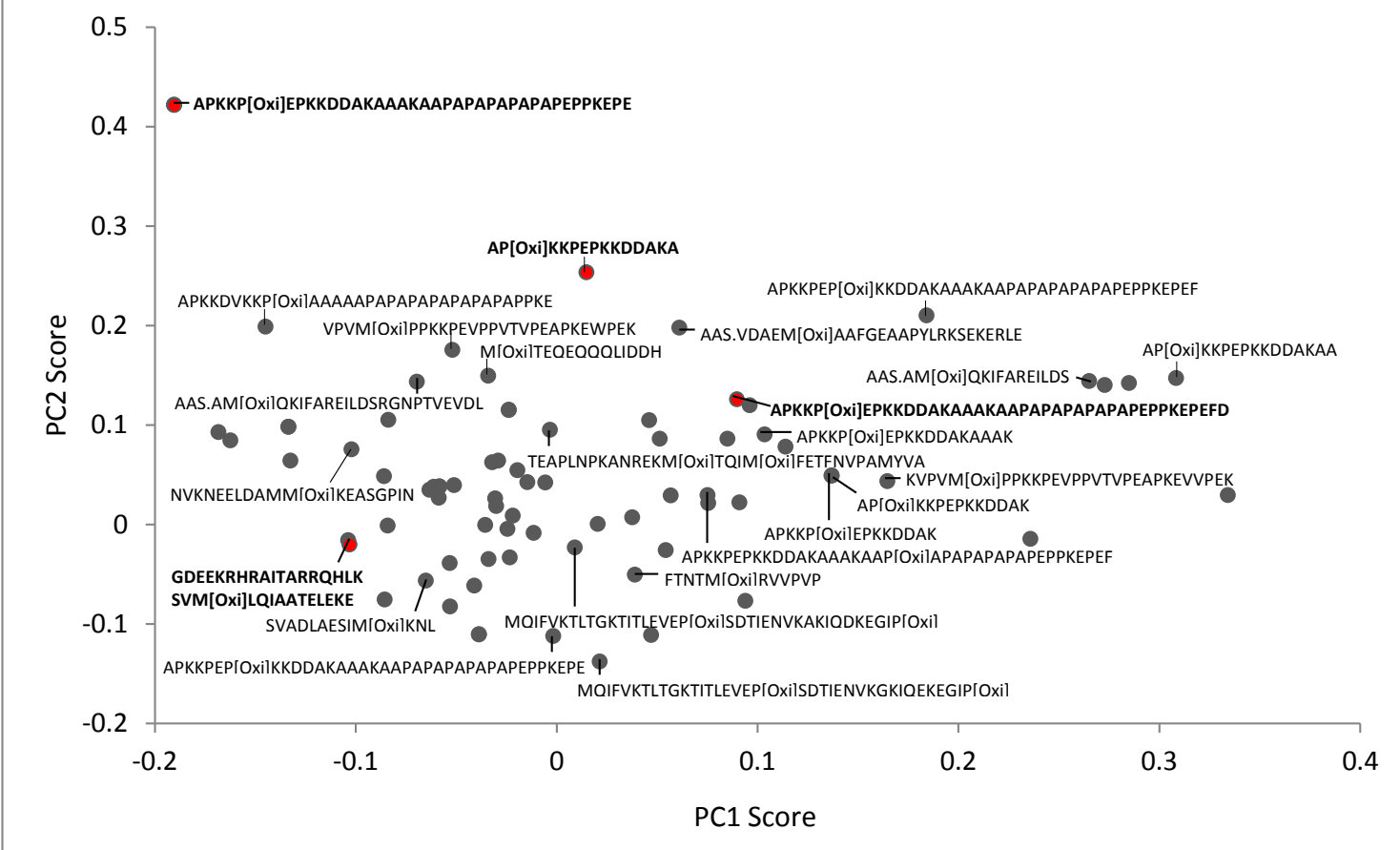

Figure 1. 
A)

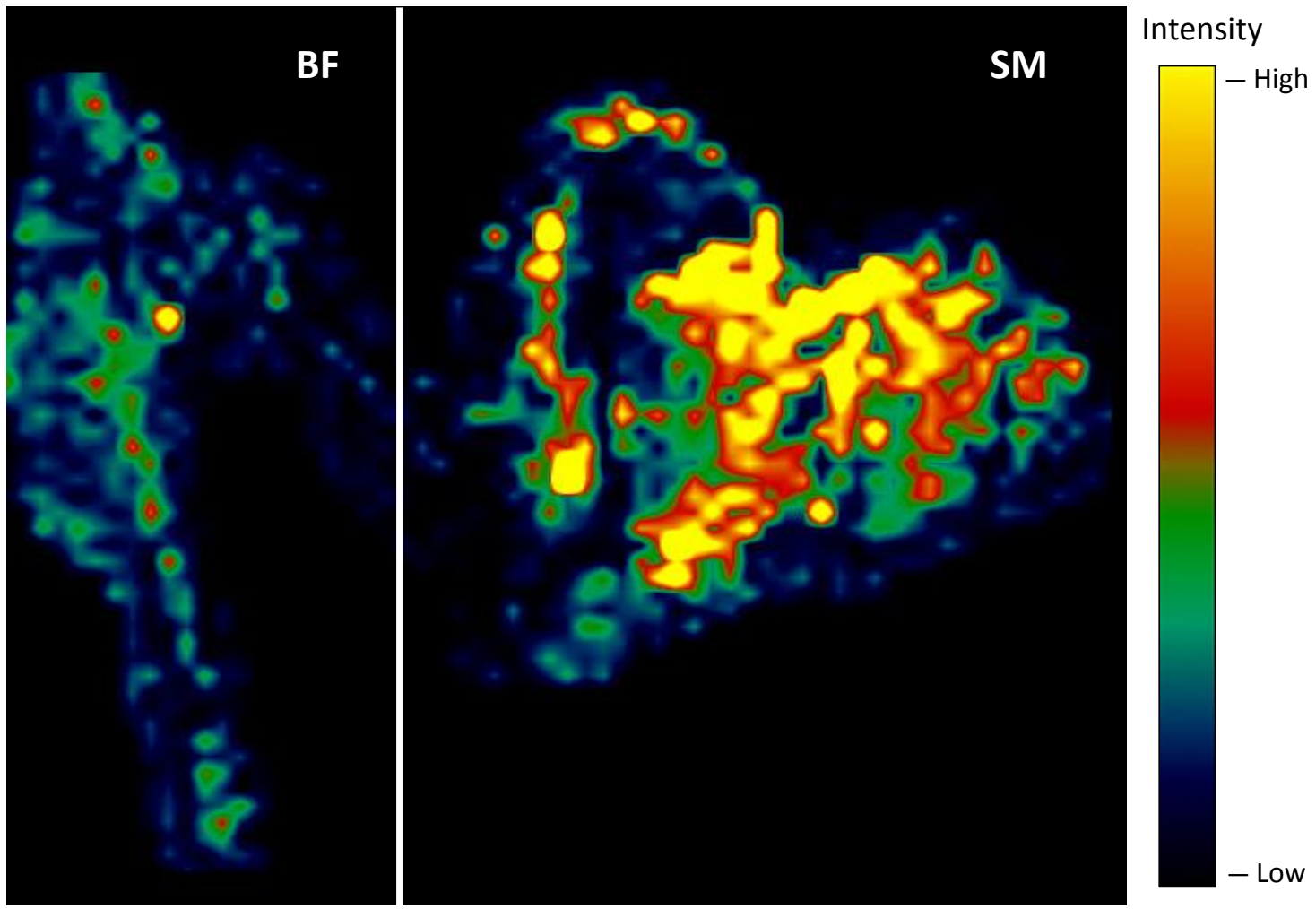

B)

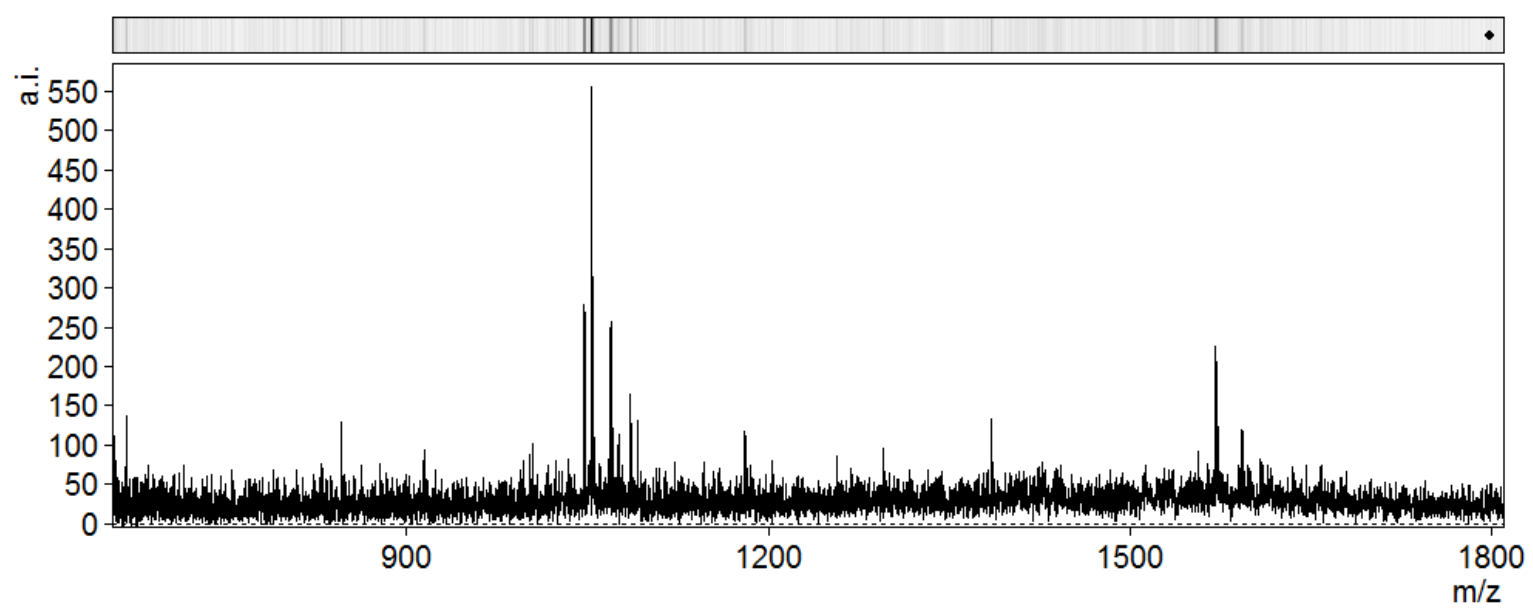

Figure 2. 
Table 1. Number of oxidised peptides derived from main proteins identified by LC-MS/MS in S,

\begin{tabular}{llc}
\hline Dry-cured ham muscle & Protein name & $\begin{array}{c}\text { Protein } \\
\text { abbreviation }\end{array}$ \\
\cline { 2 - 3 } & Actin & ACTIN \\
& Myosin & MYO \\
& Titin & TITIN \\
& Troponin & TROP \\
& Creatine kinase & CK \\
& Pyruvate kinase & PK \\
& Beta-enolase & ENO \\
& Glyceraldehyde-3-phosphate dehydrogenase & G3PDH \\
& Phosphoglycerate kinase & PGK \\
& Lactate dehydrogenase & LDH \\
\hline & Actin & ACTIN \\
& Myosin & MYO \\
& Titin & TITIN \\
& Troponin & TROP \\
& Creatine kinase & CK \\
Biceps femoris & Pyruvate kinase & PK \\
& Beta-enolase & ENO \\
& Glyceraldehyde-3-phosphate dehydrogenase & G3PDH \\
& Phosphoglycerate kinase & PGK \\
& Lactate dehydrogenase & LDH \\
\hline
\end{tabular}

${ }^{\mathrm{a}}$ Number of oxidised peptides identified in the protein. ${ }^{b}$ Number of unoxidised peptides identified it 
Table 2. Number of peptides showing oxidation of different amino acids identified by LC-MS/MS in Semimembranosus and Biceps femoris muscles.

\begin{tabular}{|c|c|c|c|c|c|c|}
\hline Dry-cured ham muscle & Amino acid & Monoxidation $^{\mathrm{a}}$ & Dioxidation $^{\mathrm{b}}$ & Trioxidation $^{c}$ & Total $^{d}$ & Percentage (\%) $^{\mathrm{e}}$ \\
\hline \multirow{4}{*}{ Semimembranosus } & Methionine (Met) & 52 & 6 & & 58 & 77.33 \\
\hline & Cysteine (Cys) & 2 & 6 & 2 & 10 & 13.33 \\
\hline & Histidine (His) & 4 & & & 4 & 5.33 \\
\hline & Tryptophan (Trp) & 2 & 1 & & 3 & 4.00 \\
\hline \multirow{5}{*}{ Biceps femoris } & Methionine (Met) & 53 & 6 & & 59 & 84.29 \\
\hline & Cysteine (Cys) & 2 & 2 & 1 & 5 & 7.14 \\
\hline & Histidine (His) & 3 & & & 3 & 4.29 \\
\hline & Tryptophan (Trp) & & 1 & & 1 & 1.43 \\
\hline & Phenylalanine (Phe) & & 2 & & 2 & 2.86 \\
\hline
\end{tabular}

$\overline{a, b, c}$ Number of peptides with addition of one, two, or three oxygen atoms at the amino acid residue. ${ }^{\mathrm{d}}$ Total number of peptides identified showing oxidation of the amino acid. ${ }^{e}$ Percentage that represents the number of peptides with the amino acid oxidation in relation to the total of oxidised peptides identified in the muscle. 


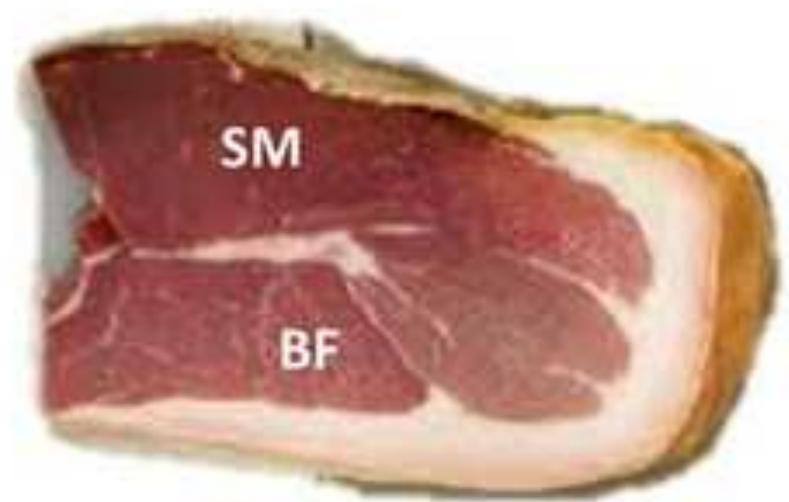

Dry-cured ham samples

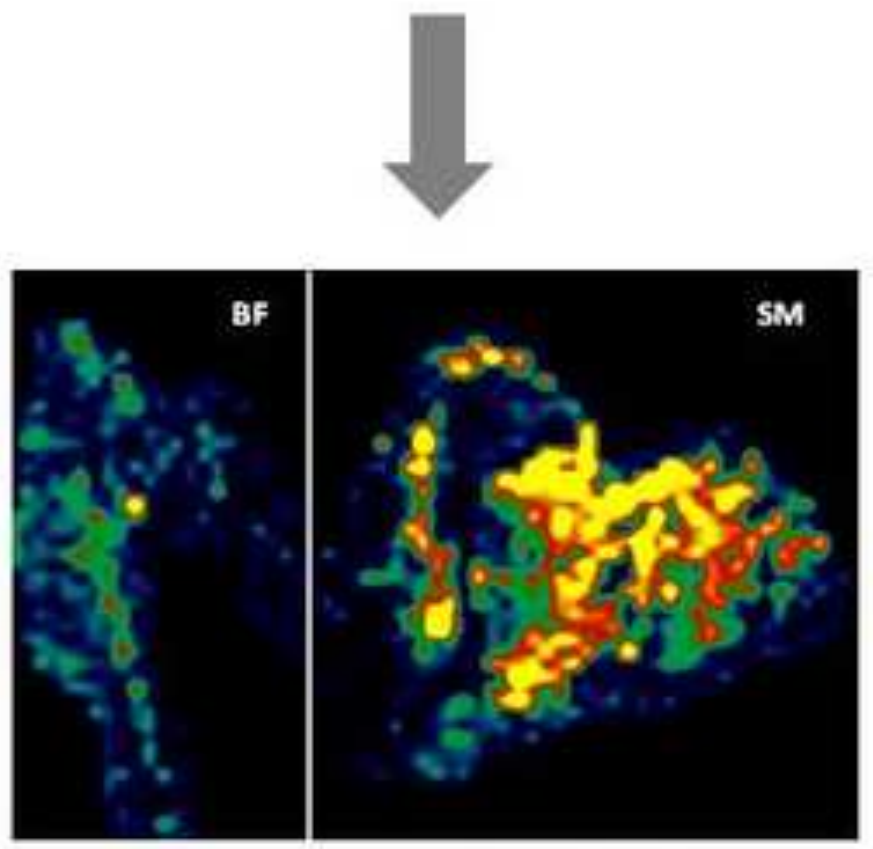

MALDI-IMS analysis

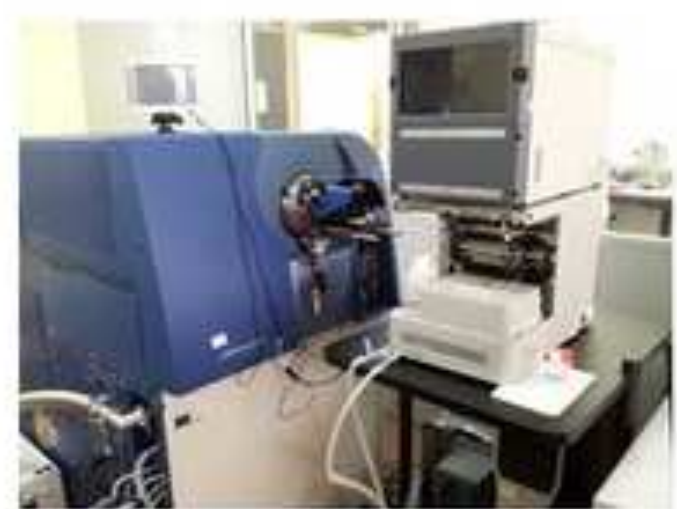

nLC-MS/MS analysis

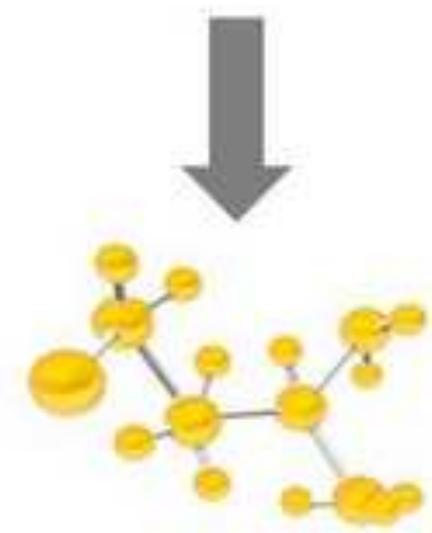

Identification and relative quantification of oxidised peptides 